\title{
RESENHA DE TEMPO REENCONTRADO: ENSAIOS SOBRE ARTE E LITERATURA, DE ALEXANDRE EULÁLIO
}

\author{
REVIEW OF TEMPO REENCONTRADO: ENSAIOS SOBRE \\ ARTE E LITERATURA, BY ALEXANDRE EULÁLIO
}

EULÁLIO, Alexandre. Tempo reencontrado: ensaios sobre arte e literatura. Organização de Carlos Augusto Calil. São Paulo: Instituto Moreira Salles; Editora 34, 2012. 272p.

\author{
Pedro Meira Monteiro \\ Princeton University \\ Princeton (NJ), Estados Unidos
}

Painel da mais luxuosa inteligência crítica, lidando com os séculos XIX e XX, Tempo reencontrado tem como núcleo, segundo seu organizador, três textos, dois dos quais dedicados a Machado de Assis. Bem ao estilo de Alexandre Eulálio, são ensaios que se situam a cavaleiro das artes plásticas e da literatura, contemplando aquele que foi o último espetáculo do poder do Império brasileiro, no episódio conhecido como baile da Ilha Fiscal, ocorrido às vésperas da proclamação da República no Rio de Janeiro.

O magnífico ensaio "Esaú e Jacó: narrador e personagens diante do espelho", publicado em 1971 em italiano, faz-se agora disponível em português, embora uma versão preliminar, correspondendo à conferência homônima que Alexandre Eulálio deu em Princeton em 1968, fosse já conhecida do público brasileiro, graças à antologia organizada, em seguida à morte do crítico, por Berta Waldman e Luiz Dantas (Escritos. Campinas; São Paulo: Editora da Unicamp; Editora Unesp, 1992). Este é também o caso do segundo ensaio deste núcleo da antologia organizada agora por Carlos Augusto Calil, intitulado "De um capítulo de Esaú e Jacó ao painel d'O último baile. Literatura e pintura no Brasil: simpatias, diferenças, interações. Um caso-tipo: Aurélio de Figueiredo e Machado de Assis". Limito-me aqui a resenhar os dois ensaios, momentos altos da crítica literária brasileira e machadiana. 
"Romance de fim de vindima" é como Alexandre Eulálio chama Esaú e Jacó, livro no qual uma verdadeira arte do "apólogo" teria sido levada às últimas consequências. Num de seus brilhantes jogos de iluminação, quando o crítico de arte e o de literatura são um só, o autor compara o penúltimo romance machadiano a um gigantesco painel pontilhista, sugerindo que, "partindo da vibração líquida das pinceladas cromaticamente contrastantes" e obtendo "no conjunto um repouso definitivo e coerente", ninguém menos que Seurat ofereceria "aos nossos olhos como uma representação plástica e simbólica ideal do romance machadiano" (p. 114).

Neste como em outros momentos, o texto de Alexandre Eulálio exige do leitor que respire fundo, porque são verdadeiras acrobacias aéreas que se projetam no plano da imaginação crítica. Comparatista não apenas de tradições nacionais diversas, mas interessado naquilo que a pintura diz da literatura e vice-versa, quando recorre a Seurat o crítico está fixando um problema central da narrativa machadiana: cultivada pela pena ágil do cronista, a "história curta" saltita no tecido do romance, marcando uma sincopação "emocional e representativa" que nos leva ao quadro Un Dimanche à la Grande Jatte, em que se anuncia porventura o que mais tarde será elaborado sobre o caráter fantasmático da cena do último baile do Império: "decompondo atomisticamente as aparências, com a intenção de chegar a uma realidade espectral harmoniosamente caligráfica, ambos os artistas [Seurat e Machado] apontam para uma representação essencial da existência que, em sua silenciosa exemplaridade, aproxima-se de modo irresistível do simbolismo alegórico" (p. 114).

Um bom leitor de Machado de Assis, conhecedor de sua fortuna crítica, logo reconhecerá, como que prefigurado no salto imaginoso do ensaísta, todo o debate em torno do caráter alegórico da narrativa, núcleo vulcânico da crítica sobre o bruxo do Cosme Velho. Basta lembrar que a vertente de uma leitura mais "sociológica" dos textos machadianos, historicamente determinada, é amiúde identificada à cunha alegorizante. Dando nome aos bois: Alfredo Bosi é talvez o crítico mais ferino da insuficiência da leitura alegorizante que, mediada pela crítica sociológica, está em Roberto Schwarz e dele se espraia para chegar a um John Gledson. Mas é curioso que, inspirado em Augusto Meyer, Alexandre Eulálio coincida grandemente com o que mais tarde proporia Bosi, na esteira do mesmo Meyer, ao lembrar as fontes do olhar machadiano, ou aquilo que, nas palavras de Eulálio, era a "vocação de moralista, 
entendida ao modo clássico", do nosso bruxo. Em resumo, nem só de alegoria se faz uma boa ficção: "Narrador complexo e cheio de matizes, Machado de Assis, embora interessado de modo direto pelo conteúdo abstrato da alegoria, não abdicava do intento de, na ficção, recriar a vida em todos os seus refolhos" (p. 110).

Os apólogos são os pontos pequenos em que é banhado o olhar, levado entretanto a uma visão de conjunto que oscila e deixa o leitor "meio desamparado", sempre deslizando por entre os núcleos apologais, historietas "improváveis do ponto de vista naturalista embora fiéis ao verossímil", existindo "contudo fora do clima de caricatura, ainda que possuam fortes pinceladas parodísticas" (p. 115).

Um pouco ao gosto dos diagramas que encantaram a crítica da linguagem nos anos sessenta, uma das extensas e preciosas notas ao fim do texto mapeia o ponto de vista machadiano em Esaú e Jacó, verdadeira "máquina de narrar" (como a "máquina de morar" de Le Corbusier, sugere o crítico). No desenho preciso e esclarecedor, o olhar do "Demiurgo-narrador" se estende ao infinito e contém o ponto de vista do conselheiro Aires, em que "diálogo, diário, pensamento" esfumam-se (aqui fala o crítico de pintura, atento ao claro-escuro machadiano) numa "área de reticência": aquilo que "Aires não disse" ou "não explicou" misteriosamente se impõe ao olhar. Também aqui, o leitor contemporâneo poderá se divertir confrontando as observações pioneiras de Alexandre Eulálio às reflexões de um Abel Barros Baptista sobre a rasura do autor e as complicações daí advindas, quando o seu nome emerge para dar sentido ao livro. Não se trata apenas de perguntar "quem escreve?", mas de notar a complexidade moderna da fatura machadiana:

Vale acrescentar que o cone visual de Aires é tacitamente envolto pelo que podemos denominar margem de manipulação do Narrador. Maquinaria sutil que permite ao Demiurgo afastar-se do seu porta-voz parcial quando quer que Aires, a despeito da posição preferencial que ocupa no centro da ação, abandone seu camarote e participe do espetáculo como as demais personagens. (p. 130-131)

Note-se ainda que, ao contemplar a reticência, essa zona de manipulação provém de um olhar que permite aproximar Machado de Assis de André Gide. Entranhado na narrativa, o 
diário de Aires possui função semelhante àquela do de Edouard, em Les Faux-monnayeurs: a sua função é diferenciar os planos da criação segundo um ponto de vista preciso e limitado, diferente do autor. Mas se na obra sinfônica de Gide esta atitude acompanha um critério de decomposição do real que já foi até relacionado [...] ao espírito da síntese analítica do Cubismo plástico, seu contemporâneo, em Machado de Assis a moldura gráfica, assimétrica e fantasista, que devemos ao narrador, segue antes o gosto floreal do modern style - o narrador, com a sua caprichosa excentricidade de comentar a obra e dialogar com o leitor, cria uma moldura caligráfica que ao mesmo tempo separa e integra, num movimento de ida e volta, o absoluto da criação romanesca e a relatividade do seu existir em livro. (p. 120)

Mais uma extensa e polpuda nota esclarece, entretanto, que a novidade formal compartilhada tem raiz numa visão de mundo comum:

Se a aproximação de dois autores tão díspares como André Gide e Machado de Assis pode à primeira vista parecer estranha ou até artificiosa, ela se revela natural numa análise mais detida. Os dois têm em comum a filiação egoísta: Montaigne, Pascal, os grandes moralistas, Swift, Voltaire, Diderot, Stendhal. Sua especial predileção pela esfumatura psicológica e pelos contrastes de temperamento é exercitada em determinados ambientes sociais, nos quais se representa uma farsa de sentimentos e interesses, no pior dos casos aliados a uma ética de ostentação. (p. 132)

A arriscada hipótese de Alexandre Eulálio, por fim, é que a tela de Aurélio de Figueiredo, $O$ último baile da Monarquia (na verdade intitulado pelo próprio Figueiredo A ilusão do Terceiro Reinado), é uma "glosa indireta, livremente reconstruída pelo pintor a partir da sugestão" do texto machadiano, especificamente o capítulo "Terpsícore" de Esaú e Jacó (p. 141). A sutil ironia de Eulálio, aliás, não nos deixa esquecer que a hipótese crítica nascera com o professor de literatura que, em 1980, num curso no Instituto de Estudos da Linguagem da Unicamp, fez todo o núcleo de suas preocupações preceder as "leituras teóricas" recomendadas pela burocracia acadêmica. Sorte dos alunos.

A fertilização recíproca dos campos de interesse, afrontando qualquer pudor pela "especialização" do saber que era tão forte à época, permite ao crítico imaginar o 
encantamento de Aurélio de Figueiredo - que aliás esteve no próprio baile da Ilha Fiscal - diante da cena reconstruída ficcionalmente por Machado em Esaú e Jacó. Mas permite também que se pergunte se, ao descrever a esquiva e contemplativa Flora, Machado de Assis não teria talvez tido acesso aos "belíssimos estudos fotográficos" em que Marc Ferrez flagrou o momento em que, no Paço Imperial,

Dona Isabel, em pé, de perfil, apoia-se absorta ao piano-armário, o olhar perdido através da ampla porta-janela, cujos reposteiros e cortina contêm mal e mal a exuberante luminosidade exterior. A poderosa atmosfera "proustiana" dessas imagens, evidentemente executadas por um mestre da câmara fixa, recupera, com pungência toda especial, dois momentos sucessivos de um tempo perdido. Momentos que parecem ter sido evocados com inteira fidelidade no romance quando a moça Flora, no baile da Ilha, sonha para si a suprema liberdade da futura soberana: decidir quando e como "pode ficar só, no mais recôndito do Paço, fartando-se de contemplação e música". (p. 164)

O retrato psicológico, disparado talvez pela fotografia da princesa pensativa, permite compreender as "pinceladas de mestre" do próprio Machado, que poria seus personagens a circular naquela ilha que era, nas palavras do narrador de Esaú e Jacó, uma "cesta de luzes no meio da escuridão tranquila do mar" (p. 143). Repare-se que o leitor do ensaio é também convidado a valsar, da fotografia ao texto (num diálogo de resto vertiginoso entre texto e paratexto, rodapé e ensaio), e deste finalmente à pintura que, em 1905, no ano seguinte à publicação de Esaú e Jacó, radicalizaria, por seu turno, a alegorização da cena, como pode ver o leitor na excelente reprodução do quadro que está neste Tempo reencontrado. Quadro que, aprenderá o mesmo leitor, Mario Praz considerou "assai brutto", reconhecendo-o entretanto como "uno dei più parlanti documenti del gusto d'un epoca" (p. 162).

Na parte superior da tela, sobre o cais em que estão os convidados, e sobre a baía iluminada e as montanhas do Rio, confrontam-se dois futuros: Isabel é coroada, dando início ao Terceiro Império, enquanto a República avança, sob o pavilhão do novo regime. $\mathrm{Na}$ análise finíssima, impossível de ser resumida, Alexandre Eulalio descobre por onde caminha o olhar do espectador do quadro, cuja arquitetura o faz convergir para o céu alegórico, que opera como um "pressentimento", resultando daí uma cena, dirá 
ainda o crítico, "que deve ser descoberta apenas pelo observador, como inúmeras vezes se dirige diretamente ao leitor o narrador machadiano" (p. 146). E se no quadro de Aurélio de Figueiredo a definição acadêmica dos contornos cede, quando se trata da coroação de Isabel, a certo impressionismo e a uma representação "literalmente nefelibata", que aponta para o gosto estético dos "salões esotéricos" finisseculares, será preciso lembrar que a pintura, ao menos aqui, não possui o distanciamento dado "pelo tom sardônico do Narrador do romance" (p. 147). O que não impedirá, porém, que o crítico sugira uma série de convergências entre o pintor e o escritor, em especial no contraste entre o céu ideal da República e o Império que, no mesmo céu, é uma espécie de sinal pressago do futuro irrealizado, pairando como "festa baça de luz e som de certa coroação imponderável". Aí, ainda que banalizado na pintura, "permaneceria o tema machadiano da desilusão, da miragem de um momento, no qual deve ser colhido, contudo, o que nele existe de fugitivo consolo" (149). E não hesitará tampouco o crítico, num tom faceto, em convidar o leitor a que localize, na tela, os próprios personagens do romance:

no centro, um pouco à esquerda, não é difícil identificar Flora, com o leque meio aberto, seu fino perfil que quase cobre o de Pedro; Aires conversa com ambos, irônico e deferente. Bem ao lado, Santos e Natividade na companhia de um conhecido não identificado, e mais além, a robusta silhueta de Dona Cláudia, junto a Baptista, seu marido. (p. 130)

Os ensaios de Alexandre Eulálio são inesgotáveis. Deles seguem brotando luzes e faíscas, sob as quais aparecerão Sousândrade, também interessado na figura de Isabel, Raul Pompeia, igualmente obsedado pela queda da Monarquia, ou mesmo Coelho Neto, que descreveu o baile da Ilha Fiscal do ponto de vista do Cais Pharoux, num quadro que faria par, sugere ainda o crítico, não à pintura meio machadiana de Aurélio de Figueiredo, e sim ao inencontrável pastel de Honório Esteves do Sacramento, com sua intenção "meramente descritiva e documentária" (p. 156). Mas o crítico, sempre simpático às obras do espírito, encontrará, mesmo ali no Fogo Fátuo de Coelho Neto, um "livro poderoso", em que as qualidades e os defeitos do excesso parnasiano são expostos com lucidez. É verdade que tudo isso pertence a um mundo 
avesso a algumas das mais significativas obras do modernismo brasileiro, coetâneas a Fogo Fátuo. Mas aí já falamos de um mundo futuro, que não viveu ou viu Machado de Assis.

Pedro Meira Monteiro é professor de Literatura Brasileira na Princeton University. É autor de Um moralista nos trópicos (Boitempo), co-organizador de Sérgio Buarque de Holanda: perspectivas (Editora da Unicamp; EdUERJ), e organizador de Mário de Andrade e Sérgio Buarque de Holanda: correspondência (Companhia das Letras; EdUSP). Atualmente prepara um livro sobre o Memorial de Aires, de Machado de Assis. E-mail: <pmeira@ princeton.edu> 